\title{
Hydronephrosis associated with ureteral metastasis of prostate cancer: A rare case report
}

\author{
DONG ZHANG, HONGLIANG LI and WEIMIN GAN
}

\begin{abstract}
Department of Urology, The Second Affiliated Hospital of Xi'an Jiaotong University, Xi'an, Shaanxi 710004, P.R. China
\end{abstract}
Received September 22, 2015; Accepted December 18, 2015

DOI: $10.3892 / \operatorname{mco} .2016 .775$

\begin{abstract}
Prostate cancer is one of the most common male malignancies, although it rarely metastasizes to the ureter. The present case study reported a 63-year-old man who presented with asymptomatic right hydronephrosis, detected by ultrasound. Computed tomography urography demonstrated right hydronephrosis, secondary to thickening of the distal ureter. The patient's serum concentration of prostate specific antigen was $111.400 \mathrm{ng} / \mathrm{ml}$, and a prostate needle biopsy revealed prostate adenocarcinoma, with a Gleason score of $4+5=9$. Renal scintigraphy revealed poor excretion of the right kidney. A nephroureterectomy was subsequently performed, and a histological examination revealed a metastatic prostate adenocarcinoma of the ureter. Combined androgen blockage therapy with bicalutamide (50 mg, once daily) and goserelin (3.6 mg, once a month) was administered to the patient. At 3 months of follow-up, the patient's PSA levels had decreased to $0.322 \mathrm{ng} / \mathrm{ml}$; at 6 months of follow-up, the PSA levels had further decreased to $0.136 \mathrm{ng} / \mathrm{ml}$.
\end{abstract}

\section{Introduction}

The ureter is a rare location of metastasis, irrespective of the primary cancer lesion (1). The most common malignant tumors metastasizing to the ureter are breast cancer and stomach cancer, whereas colon, cervix and rectum cancers also metastasize to the ureter with an appreciable frequency (1). However, ureteral metastasis from prostate cancer is extremely rare (2). The present case study reported such an incidence of a patient presenting hydronephrosis secondary to ureteral metastasis of prostate cancer.

Correspondence to: Dr Hongliang Li, Department of Urology, The Second Affiliated Hospital of Xi'an Jiaotong University, 157 West Fifth Road, Xi'an, Shaanxi 710004, P.R. China

E-mail: hh1999@163.com

Key words: ureter metastasis, prostate cancer, hydronephrosis, loss of renal function

\section{Case report}

A 63-year-old man presented with asymptomatic right hydronephrosis, detected by ultrasound in our department. Computed tomography urography (CTU; SOMATOM ${ }^{\circledR}$ Definition Flash, Siemens Healthcare, Erlangen, Germany) demonstrated right hydronephrosis, a dilated middle-upper ureter secondary to thickening of the distal ureter (Fig. 1), and benign prostatic hyperplasia $(\mathrm{BPH})$. The result of the urine analysis was negative for hematuria. The serum prostate specific antigen (PSA) concentration was $111.400 \mathrm{ng} / \mathrm{ml}$. A digital rectal examination revealed an enlarged and stony hard prostate gland, and subsequent prostate needle biopsy revealed prostate adenocarcinoma, with a Gleason score of $4+5=9$. Renal dynamic scintigraphy revealed that the glomerular filtration rate was only $10.56 \mathrm{ml} / \mathrm{min}$ on the right side. Fluorescence in situ hybridization of the exfoliated cells in the urine did not reveal any evidence of malignancy.

On the basis of the results mentioned above, ureteroscopy was performed to determine whether the lesion of the distal ureter was transitional cell carcinoma (TCC) or metastasis of prostate cancer. The bladder wall and the right ureteral orifice were thickened and stiff. The ureteroscopy was hard to pass the stricture of the right distal ureter, thus rendering it impossible to obtain any biopsy result. Considering the higher degree of malignancy of TCC and the poor function of the right kidney, a nephroureterectomy was performed. Following surgical excision, the tissue was immediately placed in $4 \%$ formaldehyde solution prior to paraffin embedding. Serial sections $(4 \mu \mathrm{m}$ thickness) were obtained and stained with hematoxylin and eosin and 3,3'-diaminobenzidine for immunohistochemical staining. The histology results demonstrated a metastatic prostatic adenocarcinoma of the ureter. Immunohistochemical staining revealed that the PSA and P504 were positive. Combined androgen blockade therapy with bicalutamide (50 mg, once daily) and goserelin (3.6 mg, once a month) was then administered to the patient. At 3 months of follow-up, the patient's PSA levels had decreased to $0.322 \mathrm{ng} / \mathrm{ml}$; at 6 months of follow-up, the PSA levels had further decreased to $0.136 \mathrm{ng} / \mathrm{ml}$.

\section{Discussion}

The most common metastatic sites of prostate cancer are the lymph nodes and bone. The lung, bladder, liver and adrenal 

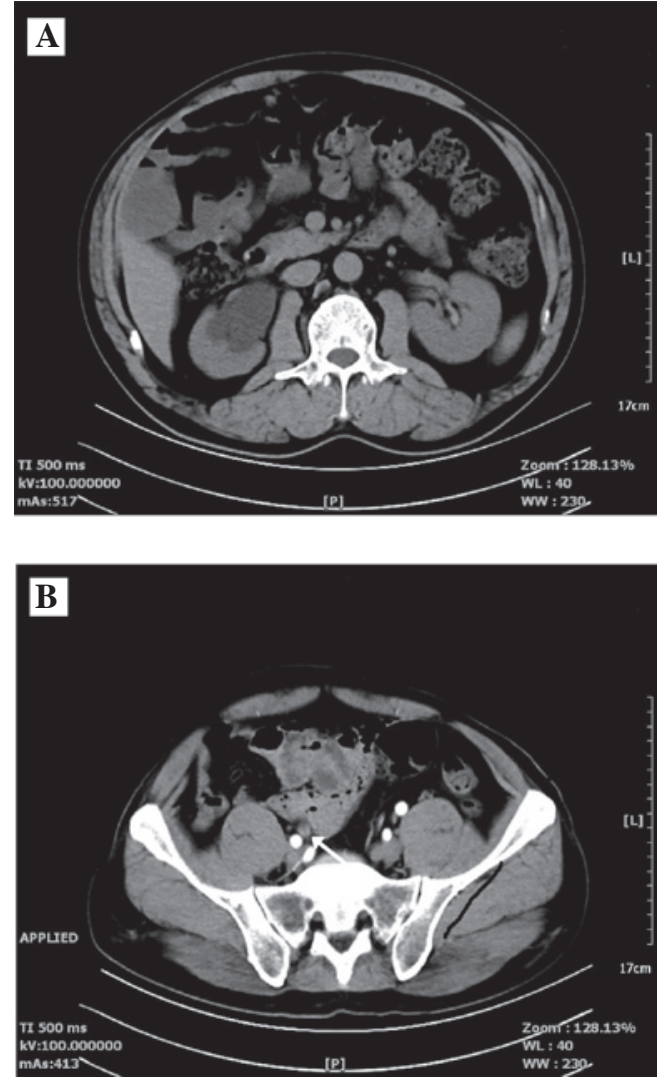

Figure 1. CT images of the abdomen. (A) The CT revealed the right hydronephrosis and (B) a thickening of the right distal ureter (illustrated by the white arrow). CT, computed tomography.

gland are other sites where metastasis occurs comparatively commonly. By contrast, ureteral metastasis of prostate cancer rarely occurs. In 1999, a total of 38 cases of ureteral metastases of prostate cancer were collected and reviewed by Haddad (2). Since then, several novel cases have been reported over the last 10 years (3-7). Among these cases, the most commonly reported symptom of ureteral metastasis is flank pain (15-50\%) due to ureteral obstruction. Hematuria is not often identified. This may be due to the fact that the majority of ureteral tumors from distant primary sites are made by metastases beneath the mucosa, or they invade from surrounding tissues of the ureter. In the present case study, the patient had no subjective symptoms. CTU, retrograde pyelography and ureteroscopy may be useful for differential diagnosis in patients with prostate cancer who present with urinary obstruction symptoms.

The most common malignant tumors metastasizing to the ureter are breast cancer and stomach cancer (1), whereas colon, cervix, and rectum cancers also metastasize to the ureter relatively commonly. However, ureteral metastasis from prostate cancer is a rare occurrence. It often arises as a consequence of direct invasion of a prostate cancer or compression by lymphadenopathy. In the present case study, the patient's prostate cancer had most likely been caused by direct invasion, since the bladder wall and the right ureteral orifice were thickened and stiffened, as observed during ureteroscopy.

Hydronephrosis associated with ureteral stenosis/obstruction may be an early indicator of when the ureter is involved in prostatic cancer metastasis. Benign lesions, such as BPH and stones, should be taken into consideration first of all for differential diagnosis. In the present case, the possibility of metastatic prostate cancer would have been considered when evidence arose which indicated a malignant origin. However, the ureteroscopy proved hard to pass the stricture of the distal ureter, and biopsy results were not obtainable. Considering the higher degree of malignancy of TCC and the poor function of the right kidney, a nephroureterectomy was performed. A pathological examination revealed metastatic prostate adenocarcinoma.

In conclusion, the present case study details an unusual first presentation of prostate cancer without subjective symptoms. Metastatic lesions to the ureter due to prostate cancer occur very infrequently. Prostate cancer should be considered in the differential diagnosis of elderly men with lesions in the ureter, where a malignant origin is suspected. CTU, retrograde pyelography and ureteroscopy may be useful for differential diagnosis.

\section{Acknowledgements}

This study was supported by the National Natural Science Foundation of China (no. 81101937).

\section{References}

1. Fitch WP, Robinson JR and Radwin HW: Metastatic carcinoma of the ureter. Arch Surg 111: 874-876, 1976.

2. Haddad FS: Metastases to the ureter. Review of the world literature and three new case reports. J Med Liban 47: 265-271, 1999.

3. Jung JY, Kim HK, Roh YT, Choi DY, Yoo TK and Kim EK: Long-standing ureteral metastasis secondary to adenocarcinoma of the prostate after bilateral orchiectomy. J Urol 164: 1298-1299. 2000.

4. Chalasani V, Macek P, O'Neill GF and Barret W: Ureteric stricture secondary to unusual extension of prostatic adenocarcinoma. Can J Urol 17: 5031-5034, 2010.

5. Schneider S, Popp D, Denzinger S and Otto W: A rare location of metastasis from prostate cancer: Hydronephrosis associated with ureteral metastasis. Adv Urol 2012: 656023, 2012.

6. Jallad S, Turo R, Kimuli M, Smith J and Jain S: Ureteric stricture: An unusual presentation of metastatic prostate adenocarcinoma. Ann R Coll Surg Engl 94: e213-e214, 2012.

7. Huang TB, Yan Y, Liu H, Che JP, Wang GC, Liu M, Zheng JH and Yao XD: Metastatic prostate adenocarcinoma posing as urothelial carcinoma of the right ureter: A case report and literature review. Case Rep Urol 2014: 230852, 2014. 